\title{
Detecção molecular de Babesia spp. e Ehrlichia spp. em Rhipicephalus sanguineus e cães do Centro de Controle de Zoonoses de Belém, estado do Pará
}

Molecular detection of Babesia spp. and Ehrlichia spp. in Rhipicephalus sanguineus and dogs from

\author{
the Zoonoses Control Center of Belém, state of Pará
}

Detección molecular de Babesia spp. y Ehrlichia spp. en Rhipicephalus sanguineus y perros del

Centro de Control de Zoonosis de Belém, estado de Pará

Recebido: 04/10/2021 | Revisado: 12/10/2021 | Aceito: 16/10/2021 | Publicado: 19/10/2021

Gilmara Regina Santos da Silva ORCID: https://orcid.org/0000-0002-6990-0803 Universidade da Amazônia, Brasil

E-mail: gilmarasantos1505@hotmail.com

Waléria Patricio do Nascimento ORCID: https://orcid.org/0000-0003-2027-7114 Universidade da Amazônia, Brasil

E-mail: walerianascimentovet@ gmail.com

Fernanda Barbosa de Carvalho ORCID: https://orcid.org/0000-0002-1412-0359 Universidade da Amazônia, Brasil E-mail: nandavetzoo@gmail.com

Edilamar de Barros Franco

ORCID: https://orcid.org/0000-0002-2996-4052 Universidade da Amazônia, Brasil E-mail: edilamarbello@gmail.com

Madson Fabricio Martins André ORCID: https://orcid.org/0000-0001-6891-8772 Universidade da Amazônia, Brasil E-mail: madson_fisic@ hotmail.com Isabela Mesquita Araújo

ORCID: https://orcid.org/0000-0002-5471-2404 Universidade Federal Rural do Rio de Janeiro, Brasil E-mail: isabela.bio77@hotmail.com

Juliana de Almeida Coelho

ORCID: https://orcid.org/0000-0001-5755-8054 Universidade Federal Rural do Rio de Janeiro, Brasil E-mail: jln_coelho@hotmail.com

Matheus Dias Cordeiro

ORCID: https://orcid.org/0000-0003-2045-8716 Universidade Federal Rural do Rio de Janeiro, Brasil E-mail: mathcordeiro@hotmail.com

Adivaldo Henrique da Fonseca ORCID: https://orcid.org/0000-0002-5834-141X Universidade Federal Rural do Rio de Janeiro, Brasil E-mail: adivaldo@ufrrj.br

Paulo Cesar Magalhães-Matos ORCID: https://orcid.org/0000-0003-1759-9307 Instituto Federal do Amapá, Brasil E-mail: paulo.matos@ifap.edu.br

\begin{abstract}
Resumo
Entre as principais hemoparasitoses que afetam os cães no Brasil e no mundo estão a Babesiose e a Erliquiose, sendo a Reação em Cadeia da Polimerase (PCR) o teste de maior sensibilidade e especificidade para detecção molecular dos respectivos agentes. Este trabalho teve como objetivo detectar DNA de Ehrlichia spp. e Babesia spp. em amostras de carrapatos Rhipicephalus sanguineus e no sangue de cães mantidos sob confinamento no canil do Centro de Controle de Zoonoses (CCZ) de Belém, estado do Pará. As coletas foram realizadas no período de abril a junho de 2019. As amostras avaliadas foram testadas para a detecção de DNA de Anaplasmataceae e Babesia spp. através da Reação em Cadeia da Polimerase (PCR) e Ehrlichia spp. através da Semi-Nested PCR. Foram obtidas amostras de 81 cães do CCZ, dos quais verificou-se que 74,1\% (60/81) estavam infestados por carrapatos. Dentre as amostras sanguíneas analisadas pela PCR, 2,5\% (2/81) foram positivas para Babesia spp., não havendo detecção do agente em amostras de
\end{abstract}


carrapato. Por outro lado, 13,6\% (11/81) dos cães e 0,96\% (1/104) dos carrapatos foram positivas para Ehrlichia spp. Conclui-se que os animais investigados apresentaram elevada taxa de infestação por Rhipicephalus sanguineus, observando-se também a ocorrência de Babesia spp. e Ehrlichia spp. nos cães do Centro de Controle de Zoonoses de Belém, estado do Pará.

Palavras-chave: Babesiose; Erliquiose; DNA; Hemoparasitoses; PCR.

\begin{abstract}
Among the main hemoparasitosis that affect dogs in Brazil and in the world are Babesiosis and Ehrlichiosis, with the Polymerase Chain Reaction (PCR) being the most sensitive and specific test for molecular detection of the respective agents. This work aimed to detect DNA from Ehrlichia spp. and Babesia spp. in samples of Rhipicephalus sanguineus ticks and in the blood of dogs kept in confinement in the Zoonoses Control Center (CCZ) kennel in Belém, Pará State. The collections were carried out from April to June 2019. The evaluated samples were tested for the detection of DNA from Anaplasmataceae and Babesia spp. through Polymerase Chain Reaction (PCR) and Ehrlichia spp. through Semi-Nested PCR. Samples were obtained from $81 \mathrm{dogs}$ from the CCZ, of which $74.1 \%(60 / 81)$ were found to be infested with ticks. Among the blood samples analyzed by PCR, 2.5\% (2/81) were positive for Babesia spp., with no detection of the agent in tick samples. On the other hand, $13.6 \%(11 / 81)$ of dogs and $0.96 \%(1 / 104)$ of ticks were positive for Ehrlichia spp. It is concluded that the investigated animals presented a high rate of infestation by Rhipicephalus sanguineus, also observing the occurrence of Babesia spp. and Ehrlichia spp. in dogs from the Zoonoses Control Center in Belém, Pará state.
\end{abstract}

Keywords: Babesiosis; Ehrlichiosis; DNA; Hemoparasitosis; PCR.

\title{
Resumen
}

Entre las principales hemoparasitosis que afectan a los perros en Brasil y en el mundo se encuentran la Babesiosis y la Ehrlichiosis, siendo la Reacción en Cadena de la Polimerasa (PCR) la prueba más sensible y específica para la detección molecular de los respectivos agentes. Este trabajo tuvo como objetivo detectar ADN de Ehrlichia spp. y Babesia spp. en muestras de garrapatas Rhipicephalus sanguineus y en sangre de perros confinados en la perrera del Centro de Control de Zoonosis (CCZ) en Belém, Estado de Pará. Las recolecciones se llevaron a cabo de abril a junio de 2019. Las muestras evaluadas se analizaron para la detección de ADN de Anaplasmataceae y Babesia spp. a través de la reacción en cadena de la polimerasa (PCR) y Ehrlichia spp. mediante PCR semi-Nested. Se obtuvieron muestras de 81 perros del CCZ, de los cuales se encontró que el 74,1\% (60/81) estaban infestados de garrapatas. Entre las muestras de sangre analizadas por PCR, el 2,5\% (2/81) resultaron positivas para Babesia spp., Sin detección del agente en muestras de garrapatas. Por otro lado, el 13,6\% (11/81) de los perros y el 0,96\% (1/104) de las garrapatas fueron positivos para Ehrlichia spp. Se concluye que los animales investigados presentaron una alta tasa de infestación por Rhipicephalus sanguineus, observándose también la ocurrencia de Babesia spp. y Ehrlichia spp. en perros del Centro de Control de Zoonosis de Belém, estado de Pará.

Palabras clave: Babesiosis; Ehrlichiosis; ADN; Hemoparasitosis; PCR.

\section{Introdução}

O controle populacional de animais e das doenças por eles transmitidas configura-se como um desafio para saúde pública e depende da atuação direta de órgãos governamentais (Barroso; Lima, 2012), tais como os Centros de Controle de Zoonoses (CCZ). Esses apresentam-se como órgãos responsáveis pelo controle de agravos e de doenças transmitidas por animais, através de programas de controle populacional e da contenção de populações de animais sinantrópicos (Alves et al., 2005).

Tendo em vista que o aumento da população de cães pode ser um fator para determinação da prevalência de agentes etiológicos transmitidos por carrapatos, é necessária a implantação de medidas que visem inibir o aumento desordenado de animais, já que os cães além de serem sentinelas epidemiológicos, também são considerados hospedeiros amplificadores de carrapatos, maximizando o número de vetores no ambiente e desencadeando com isso o aumento de patógenos (Silva et al., 2017).

Entre as principais hemoparasitoses que afetam os animais domésticos no Brasil e no mundo estão a Babesiose, a Erliquiose, a Anaplasmose e a Hepatozoonose, consideradas enzooses no território brasileiro (Otranto; Dantas-Torres, 2010). A distribuição geográfica dessas enfermidades está diretamente relacionada com a de seus vetores, sendo amplamente distribuída no Brasil. Isso ocorre devido essas regiões possuírem condições edafoclimáticas adequadas para o desenvolvimento dos vetores invertebrados, principalmente relacionadas à temperatura e umidade relativa (Costa Junior, 2007). 
Estudos relacionados à identificação de hemoparasitoses e agentes patogênicos transmitidos por carrapatos têm como finalidade o controle e a prevenção de tais doenças, podendo fornecer dados de incidência, fatores de risco e fonte de exposição antes que ocorra contaminação a humanos (Vieira, 2017). Nesse sentido, o objetivo deste trabalho foi realizar a detecção molecular de Babesia spp. e Ehrlichia spp. em carrapatos e cães mantidos no canil do Centro de Controle de Zoonoses de Belém, estado do Pará.

\section{Metodologia}

\subsection{Tipo de estudo e obtenção das amostras}

A presente pesquisa trata-se de um estudo epidemiológico observacional, descritivo e, pelo tipo de informações levantadas, apresenta caráter quantitativo (Medronho et al., 2009).

As coletas foram realizadas no período de abril a junho de 2019. Os cães sob confinamento eram oriundos de vários bairros da cidade de Belém e encontravam-se alojados em nove setores do canil do CCZ, o qual possui em média 20 animais por setor. Com base nas informações fornecidas pelos funcionários do CCZ, considerou-se a população canina total de aproximadamente 150 animais. O cálculo amostral foi realizado pela prevalência esperada (software EpiInfoTM), utilizando-se nível de confiança de $95 \%$ e erro de 6\%, obtendo-se um número amostral mínimo de 81 animais.

Para a coleta das amostras, os animais foram contidos fisicamente e utilizou-se focinheira e cambão quando necessários. As amostras de sangue total foram coletadas sem distinção de sexo, raça, idade, manejo nutricional e hábitos de vida. Cada espécime foi submetida à coleta sanguínea por intermédio da punção das veias jugular ou cefálica, utilizando-se agulhas de 30x7 e seringas de 3mL. As amostras foram posteriormente acondicionadas em tubos contendo Ácido Etilenodiamino Tetra-acético (EDTA) e identificadas quanto ao número de controle do animal, sendo subsequentemente armazenadas sob congelamento à $-20^{\circ} \mathrm{C}$ até o processamento.

Os animais que foram submetidos a coleta de sangue também foram investigados quanto à infestação por carrapatos, dos quais eram coletados até dois espécimes por animal. Os carrapatos foram identificados morfologicamente utilizando a chave taxonômica de Barros-Battesti et al. (2006), sendo separados individualmente em tubos de polipropileno de $2 \mathrm{~mL}$ e congelados à $-20^{\circ} \mathrm{C}$ até o processamento.

\subsection{Processamento das amostras}

A extração de DNA das amostras de sangue foi realizada utilizando-se o protocolo Fenol-Clorofórmio de Sambrook e Russel (2001) com algumas modificações estabelecidas pelo laboratório. Para a extração de DNA dos carrapatos utilizou-se um protocolo de extração pelo método de Fenol-Clorofórmio segundo Santolin (2014). Após extraídas, os tubos contendo DNA foram identificados e armazenados em freezer a $-20^{\circ} \mathrm{C}$ até o momento da análise molecular.

\subsection{Análises moleculares}

As amostras avaliadas no presente trabalho foram testadas para a deteç̧ão de DNA de Anaplasmataceae e Babesia spp. através da Reação em Cadeia da Polimerase (PCR) e de DNA de Ehrlichia spp. através da Semi-Nested PCR.

Para a pesquisa de DNA de Ehrlichia spp. no sangue dos cães e nos carrapatos foi realizada, inicialmente, uma PCR de triagem para família Anaplasmataceae, tendo como alvo o gene 23S rRNA, com o intuito de amplificar fragmentos de DNA presentes apenas em microrganismos pertencentes à esta família. Os iniciadores empregados foram Ana23S-212f (5'-ATA AGC TGC GGG GAA TTG TC-3') e Ana23S-908r (5'-GTA ACA GGT TCG GTC CTC CA-3') na concentração de 5 pmol, que originaram fragmentos de aproximadamente 700-pb e 500-pb respectivamente, seguindo os protocolos de concentrações e condições da PCR indicados por Parola et al. (2003). O protocolo de ciclos utilizado no termociclador para PCR de 
Anaplasmataceae incluiu uma etapa de desnaturação inicial do DNA à $95^{\circ} \mathrm{C}$ por 2 minutos e 30 segundos, seguido de 40 ciclos de desnaturação à $94^{\circ} \mathrm{C}$ por 1 minuto, seguido de 1 minuto de anelamento à $55^{\circ} \mathrm{C}$ e 1 minuto de extensão à $72^{\circ} \mathrm{C}$, além da realização de um último ciclo de extensão à $72^{\circ} \mathrm{C}$ por 5 minutos, posteriormente as reações foram resfriadas à $15^{\circ} \mathrm{C}$.

Para pesquisa de DNA de Ehrlichia spp. nos carrapatos e sangue dos cães foi realizada uma Semi-Nested PCR tendo como alvo o gene Dsb. Este protocolo de PCR foi eficaz para amplificação de DNA das inúmeras espécies conhecidas do gênero Ehrlichia e teve como escopo aumentar a sensibilidade da técnica. Os iniciadores empregados na primeira reação foram DSB720 (3'-CTA TTT TAC TTC TTA AAG TTG ATA WAT C-5') e DSB330 (5'-GAT GAT GTT TGA AGA TAT SAA ACA AAT-3') na concentração de 5 pmol, que amplificou um fragmento de 401-pb. Na segunda reação foram utilizados os iniciadores DSB720 e DSB380 (5'-ATT TTT AGR GAT TTT CCA ATA CTT GG-3') na concentração de 5 pmol, que amplificou um fragmento de 349-pb, seguindo os protocolos de concentrações e condições da PCR indicados por Almeida (2011).

Na Semi-Nested PCR de Ehrlichia spp. empregou-se dois protocolos de ciclos diferentes no termociclador, um para cada reação. Na primeira reação, utilizou-se uma etapa de desnaturação inicial à $95^{\circ} \mathrm{C}$ por 4 minutos e 45 segundos, seguido de 35 ciclos consistindo de 15 segundos de desnaturação à $95^{\circ} \mathrm{C}, 30$ segundos de anelamento à $50^{\circ} \mathrm{C}$ e 30 segundos de extensão à $72^{\circ} \mathrm{C}$, realizando-se após um ciclo final de extensão à $72^{\circ} \mathrm{C}$ por 5 minutos. Na segunda reação, utilizou-se uma etapa de desnaturação inicial à $95^{\circ} \mathrm{C}$ por 4 minutos e 45 segundos, seguido de 35 ciclos consistindo de 15 segundos de desnaturação à $95{ }^{\circ} \mathrm{C}, 30$ segundos de anelamento à $52^{\circ} \mathrm{C}$ e 30 segundos de extensão à $72{ }^{\circ} \mathrm{C}$, após realizou-se um ciclo final de extensão a 72 ${ }^{\circ} \mathrm{C}$ por 5 minutos. Foram consideradas amostras positivas para Ehrlichia spp. aquelas que amplificaram DNA tanto nas reações de PCR para Anaplasmataceae quanto na Semi-Nested-PCR para Ehrlichia spp.

A pesquisa de DNA de Babesia spp. nos carrapatos e no sangue dos cães foi realizada através da PCR tendo como gene alvo 18S rRNA. Os iniciadores que foram empregados na reação foram BAB143-167 (5'-CCG TGC TAA TTG TAG GGC TAA TAC A-3') e BAB694-667 (5'-GCT TGA AAC ACT CTA RTT TCT CAA AG-3'), que amplificam um fragmento de 551pb segundo Almeida (2011). As reações tiveram como controle positivo DNA de Babesia bovis obtido de um bovino naturalmente infectado do município de Unaí, Minas Gerais, e como controle negativo, água destilada livre de DNA. O protocolo utilizado para amplificação do DNA incluiu desnaturação inicial por 5 minutos à $95^{\circ} \mathrm{C}$ e 35 ciclos repetitivos de 30 segundos a $95^{\circ} \mathrm{C}$ (desnaturação), 30 segundos à $58^{\circ} \mathrm{C}$ (anelamento), e 30 segundos à $72^{\circ} \mathrm{C}$ (extensão), seguidos por 7 minutos de extensão final à $72^{\circ} \mathrm{C}$.

\subsection{Eletroforese e fotodocumentação}

Os produtos das reações foram submetidos à eletroforese em gel de agarose com concentração de 1,5\%, sendo posteriormente corados em brometo de etídeo $(0,5 \mu \mathrm{g} / \mathrm{mL})$. O comprimento dos produtos amplificados foi estimado utilizandose um padrão de pares de base $\left(1 \mathrm{~Kb}^{\mathrm{Ludwig}}{ }^{\circledR}\right)$. A visualização dos produtos amplificados foi realizada sob luz ultravioleta em transiluminador acoplado a um sistema de fotodocumentação (ChemiDoc MP Bio-Rad $\left.{ }^{\circledR}\right)$.

\subsection{Análise estatística}

Para avaliar se a positividade para Ehrlichia apresentou diferença entre os grupo em relação ao sexo, presença de carrapatos e tratamento contra carrapatos, foi empregado o Teste Exato de Fisher. Para avaliar se essa positividade também possuía diferença de acordo com a faixa etária dos animais ( 0 - 6 meses, entre 6 e 12 meses e acima de 12 meses), foi empregado o teste ANOVA. Todas as análises foram realizadas pelo programa BioEstat 5.3 utilizando-se um nível de significância de $5 \%$. 


\section{Resultados}

Foram obtidas amostras de 81 animais cães do CCZ, sendo 29 machos e 52 fêmeas, 12 apresentavam idade média entre zero e seis meses, três entre sete e onze meses e 66 acima de um ano de idade. Do total analisado, apenas um animal era da raça Pitbull, enquanto os demais eram sem raça definida.

Do total de cães analisados, verificou-se que 74,1\% (60/81) estavam infestados por carrapatos, dos quais foram coletados 104 espécimes, sendo 39 fêmeas, 58 machos e sete ninfas de Ripicephalus sanguineus. Um total de 53,1\% (43/81) dos animais recebeu algum tratamento recente contra ectoparasitos, utilizando-se drogas a base de ivermectina e doramectina. Em contrapartida, apenas 2,5\% (2/81) dos animais foram tratados contra hemoparasitos, não sendo especificadas quais bases farmacológicas foram utilizadas. Obteve-se ainda que 39,5\% (32/81) apresentavam alguma alteração clínica, sugestiva ou não de hemoparasitoses, sendo os sinais mais frequentemente apresentados apatia, mucosas hipocoradas, caquexia, secreção ocular, pústulas e dermatites.

Através das análises moleculares observou-se que em 16\% (13/81) dos cães e 0,96\% (1/104) dos carrapatos avaliados foi detectado DNA de hemoparasitos. Não foi observada coinfecção por hemoparasitos nos animais estudados. Os resultados de acordo com a espécie de parasito e de hospedeiro são apresentados na Tabela 1.

Tabela 1 - Resultados da detecção molecular de Babesia spp. e Ehrlichia spp. em cães e carrapatos do Centro de Controle de Zoonoses de Belém, estado do Pará.

\begin{tabular}{cccc}
\hline Hospedeiros & Babesia spp. & Ehrlichia spp. & Total \\
\hline Cães & $2,5 \%(2 / 81)$ & $13,6 \%(11 / 81)$ & $16 \%(13 / 81)$ \\
Rhipicephalus sanguineus & $0 \%(0 / 104)$ & $0,96 \%(1 / 104)$ & $0,96 \%(1 / 104)$ \\
\hline
\end{tabular}

Fonte: Autores.

As amostras positivas para Babesia spp. correspondiam à duas cadelas sem raça definida, adultas, que não haviam sido tratadas contra hemoparasitoses e, embora ambas tenham recebido tratamento contra ectoparasitos, uma estava infestada por $R$. sanguineus. Os sinais clínicos apresentados por esses dois animais incluiam caquexia, apatia e mucosas hipocoradas.

Os cães positivos para Ehrlichia spp. correspondiam a seis fêmeas e cinco machos, todos com idade a partir de um ano de vida. Dez desses cães eram sem raça definida e um era da raça Pitbull. Quanto aos aspectos clínicos, 72,7\% (8/11) dos cães positivos pra Ehrlichia spp. não apresentaram sinais clínicos, enquanto que três manifestavam apatia, dermatite, caquexia e secreção ocular. Todos os animais positivos para Ehrlichia spp. encontravam-se infestados por R. sanguineus.

Não foi observada diferença significativa entre a positividade dos cães para Ehrlichia spp. nas variáveis sexo $(\mathrm{p}=0,511)$, faixa etária $(\mathrm{p}=0,285)$, presença de carrapatos $(\mathrm{p}=0,585)$ e tratamento contra ectoparasitos $(\mathrm{p}=0,108)$.

\section{Discussão}

O presente trabalho detectou DNA de hemoparasitos em cães alojados no canil do CCZ de Belém. Não é possível afirmar que a infecção de todos os animais se deu no ambiente do CCZ, uma vez que os cães, antes de admitidos no centro, possuíam hábito errante e eram oriundos de várias áreas do município de Belém, o que expõe esses animais ao risco de infestação por carrapatos infectados nos diversos ambientes. Contudo, a alta infestação por carrapatos observada nos cães, bem como os achados de carrapatos positivos para Ehrlichia spp. indicam para a possibilidade de transmissão local dos hemoparasitos, servindo de alerta para o controle desses vetores.

Neste estudo, a totalidade dos carrapatos coletados foram da espécie R. sanguineus. Segundo Jericó et al. (2015), este 
resultado possivelmente está relacionado ao ambiente urbano onde os cães parasitados estavam inseridos, sem acesso a áreas de mata ou contato com animais silvestres, o que propicia a ocorrência apenas desta espécie de artrópode. Como os cães são os hospedeiros primários para a manutenção da população de carrapatos $R$. sanguineus no ambiente, pode-se dizer que a ocorrência e a distribuição desse ectoparasito estão praticamente condicionadas à presença de cães. Todavia, nas infestações por carrapatos, o número de cães tem pouca importância na manutenção da população deste vetor, já que apenas um hospedeiro é suficiente para a realização de seu ciclo (Labruna; Pereira, 2001).

Apesar de vários estudos terem sido realizados acerca da detecção de patógenos transmitidos por carrapatos em cães no Brasil, dados sobre a prevalência da infecção nos animais da região norte ainda são escassos (Spolidorio et al., 2013; Moraes et al., 2014; Moraes et al., 2015). Os resultados desse trabalho demonstram a infestação por carrapatos e evidenciam a possibilidade de transmissão vetorial de Babesia spp. e Ehrlichia spp. em cães do CCZ de Belém, estado do Pará.

Os resultados obtidos no presente trabalho assemelham-se com o que foi descrito por Moraes et al. (2014), onde, com a utilização da metodologia da PCR convencional obteve o total de 5\% (5/100) de amostras positivas para Babesia vogeli em cães atendidos no Hospital Veterinário da Universidade Federal Rural da Amazônia, sendo este o primeiro trabalho do tipo realizado na região metropolitana de Belém.

Embora neste estudo a prevalência molecular de Babesia spp. tenha sido baixa, existe a possibilidade de que o percentual de animais infectados seja maior que o encontrado pela PCR. Na ocorrência de parasitemias muito baixas, por exemplo, é possível que mesmo a PCR não consiga detectar o DNA em algumas amostras. Isso foi comprovado na pesquisa realizada por Moraes et al. (2014), que compararam a sensibilidade de detecção entre a PCR convencional e a semi-Nested PCR e observaram que, a partir das mesmas amostras, os resultados foram significativamente diferentes: 5\% de detecção pela PCR e 22\% pela semi-Nested-PCR, confirmando a maior sensibilidade por esta técnica.

A prevalência encontrada neste trabalho foi inferior comparada aos achados de Salgado (2006), onde Babesia canis foi detectado em 10,78\% dos cães examinados no Centro de Controle de Zoonoses de Campo Grande, no Mato Grosso do Sul. No município de Governador Edison Lobão, estado do Maranhão, Silva et al. (2012) não obtiveram carrapatos positivos para Babesia canis através da detecção molecular por PCR, corroborando com os resultados deste trabalho, onde, apesar da elevada taxa de infestação por carrapatos, não houve positividade para Babesia spp.. Resultado semelhante também foi encontrado por Lopes (2006), que não observou associação positiva entre a infestação por $R$. sanguineus e a infecção por Babesia spp. Contudo, o autor destaca que isso não deve excluir a preocupação quanto à transmissão de outros agentes patogênicos.

Apatia, anorexia e palidez de mucosas foram as principais alterações observadas durante o exame físico dos cães enfermos analisados por Gonçalvez (2015), corroborando com o que foi encontrado no presente trabalho. O'Dwyer e Massard (2002) também ressaltam que esses são sinais comuns da fase aguda da doença. Apesar dos animais positivos desta pesquisa apresentarem esses sinais clínicos, é importante ressaltar que animais não infectados também apresentaram muitos desses sinais. Isso pode ser justificado pelo fato dessas manifestações serem inespecíficas, podendo estar presentes em outras enfermidades ou em quadros carenciais, comumente presentes em animais acolhidos pelos CCZ's.

O presente estudo traz importantes informações sobre a infecção por Ehrlichia spp. em cães mantidos no Centro de Controle de Zoonoses do município de Belém, estado do Pará. Foi observado que 13,58\% (11/81) dos cães e 0,96\% (1/104) de R. sanguineus avaliados foram positivos para o agente na Semi-Nested PCR. É possível que alguns dos animais mantidos no CCZ já tenham sido recebidos no estabelecimento infectados pelo agente; contudo, a presença de carrapatos positivos infestando os animais indica a possibilidade da transmissão do agente in situ.

O resultado encontrado nesta pesquisa para positividade de Ehrlichia em cães $(13,58 \%)$ corrobora com os dados levantados por Guimarães (2019) a partir de cães que foram atendidos no Hospital Veterinário da Universidade Federal Rural da Amazônia, também no município de Belém, que observou um total de 12\% (6/50) de animais positivos na PCR. 
Em contrapartida, os dados do presente trabalho diferem do encontrado por Tanikawa et al. (2013), no município de Patos, estado da Paraíba, onde observou-se apenas 3,7\% (4/108) de positividade para Ehrlichia através da Real-Time PCR. A diferença observada no percentual de positivos pode estar relacionada à origem dos animais, uma vez que neste trabalho os cães são oriundos do canil de um centro de controle de zoonoses (CCZ), de onde muitas vezes não se conhece a procedência do animal. Já nos trabalhos de Tanikawa et al. (2013) e Guimarães (2019), as amostras são provenientes de animais domiciliados atendidos em hospitais veterinários, inferindo-se assim que estes tenham recebido maiores cuidados de um tutor quanto aos aspectos sanitários.

Brandão et al. (2019) detectaram infecção simples por Ehrlichia canis através de Nested-PCR em 32,1\% (47/146) dos cães do CCZ de Belém, a partir de amostras obtidas em 2009. Esse valor é superior quando comparado ao presente trabalho $(13,6 \%)$, realizado mais de 10 anos depois e utilizando a Semi-Nested-PCR. Essa diferença pode ser justificada devido aos protocolos de controle de carrapatos utilizados no CCZ de Belém no decorrer dos anos, resultando em diminuição da infestação e consequente diminuição da infecção por agentes transmitidos por carrapatos.

Acerca da análise epidemiológica empregada por Jericó et al. (2015), pode-se mencionar que não há predisposição por sexo para infecção por erliquiose, o que também foi observado também no presente trabalho $(\mathrm{p}=0,511)$. Os autores afirmam ainda que a erliquiose pode ser diagnosticada em cães de qualquer faixa etária, como também foi confirmado no presente trabalho $(\mathrm{p}=0,285)$.

Apatia, dermatite, caquexia e secreção ocular foram os sinais clínicos observados durante o exame físico da minoria dos animais positivos para Ehrlichia spp. 27,27\% (3/11), que embora não caracterizem sinais patognomônicos da enfermidade em questão, podem ser listados como sinais clínicos observados durante a fase aguda da doença, com base nos estudos de Jericó et al. (2015).

Segundo Nelson e Couto (2015), a erliquiose pode acometer qualquer cão, mas a gravidade da mesma depende de alguns fatores, dentre eles da presença de coinfecções, como por Anaplasma platys e Bartonella spp., da dependência do microrganismo e de fatores do hospedeiro. Entretanto, E. canis isoladamente, por exemplo, não gera imunossupressão em cães jovens dentro dos primeiros meses de infecção, segundo Hess et al. (2006). Esse dado está de acordo com os obtidos na presente pesquisa, onde todos os cães positivos eram adultos e nenhum destes apresentaram sinais característicos da fase crônica da doença.

Ademais, a maioria dos animais positivos 72,7\% (8/11) apresentavam-se assintomáticos ao exame físico. Nesse sentido, Nelson e Couto (2015) afirmam que em cães as configurações clínicas das infecções por Ehrlichia, em especial $E$. canis, sofrem variações de acordo com o momento da infecção em que o animal se encontra e a duração comporta-se de forma variável na fase assintomática da doença, podendo durar meses a anos em animais naturalmente infectados, e isto pode explicar o maior percentual de animais positivos-assintomáticos no presente trabalho.

\section{Conclusão}

No presente estudo, DNA de Babesia spp. e Ehrlichia spp. foi detectado em cães e carrapatos do CCZ de Belém, estado do Pará. Verificou-se uma elevada taxa de infestação por $R$. sanguineus nos animais amostrados. A baixa prevalência de Babesia spp. não exclui a importância de análises epidemiológicas em vetores como os carrapatos, uma vez que são os responsáveis pela disseminação de vários outros hemoparasitos.

\section{Referências}

Almeida, A. P. (2011). Pesquisa de Rickettsia, Ehrlichia, Anaplasma, Babesia, Hepatozoon e Leishmania em Cachorro-do-mato (Cerdocyon thous) de vida livre do Estado do Espirito Santo. Dissertação de Mestrado em Epidemiologia Experimental Aplicada, Universidade de São Paulo, São Paulo, SP. 80p. 
Alves, M. C. G. P. et al. (2005). Dimensionamento da População de Cães e Gatos do Interior do Estado de São Paulo. Revista de Saúde Pública, São Paulo. $39,891-7$.

Barros-Battesti, D. M.; Arzua, M., \& Bechara, G. H. (2006). Carrapatos de importância médico-veterinária da região neotropical: um guia ilustrado para identificação de espécies. São Paulo, Vox/ICTTD-3/Butantan, p. 223.

Barroso, J. E. M. \& Lima, E. E. (2012). O Centro de Controle de Zoonoses e sua Importância para a Saúde Pública do Município de Catalão, GO. In: Conferência Internacional de Estratégia em Gestão, Educação e Sistemas de Informação (Ciegesi). Anais... UEG, 846-59.

Brandão, V. M. D. et al. (2019). Molecular detection of Ehrlichia canis and Anaplasma platys in dogs from municipality of Belém, State of Pará, Brazil. Ciência Rural. 49(12), 1-6.

Costa JR, L. M. (2007). Aspectos epidemiológicos de hemoparasitoses caninas no Estado de Minas Gerais: utilização de métodos de diagnóstico direto, indireto e molecular. 109 f. Dissertação (Mestrado) - Instituto de Ciências Biológicas da Universidade Federal de Minas Gerais, Belo Horizonte.

Gonçalvez, V. M. (2015). Alterações hematológicas em cães com suspeita clínica de hemoparasitoses atendidos na rotina clínica do Hospital Veterinário do $C C A, U F P B$. Trabalho de conclusão de curso em Medicina Veterinária da Universidade Federal da Paraíba. Areia, Paraíba.

Guimarães, M.C.N. (2019). Ocorrência de hemoparasitoses em cães domésticos: achados hematológicos e moleculares, 49 f. Trabalho de conclusão de curso (bacharelado em medicina veterinária) - Curso de Medicina Veterinária, Campus universitário de Belém, Universidade Federal Rural da Amazônia, Belém.

Hess, P. R. et al. (2006). Experimental Ehrlichia canis infection in the dog does not cause immuno suppression, Vet Immunol Immunopathol. 109(1-2),117-25.

Jericó, M. M., Andrade Neto, J. P. \& Kogika, M. M. (2015). Tratado de Medicina Interna de Cães e Gatos. Roca.

Labruna, M. B. \& Pereira, M. C. (2001). Carrapatos em cães no Brasil. Clínica veterinária. 6(30), 24-32.

Lopes, V. V. A. (2006). Estudo parasitológico e molecular da infecção por Babesia spp. em cães rurais do estado de São Paulo. Dissertação. (Mestrado em Clínica Veterinária) - Faculdade de Medicina Veterinária e Zootecnia. Universidade Estadual Paulista.

Medronho, R., Bloch, K. V., Luiz, R. R. \& Werneck, G. L. (2009). Epidemiologia. Atheneu, (2a ed.), 790 p.

Moraes, P. H. G. et al. (2014). Optimization of a molecular method for the diagnosis of canine babesiosis. Revista Brasileira de Parasitologia Veterinária. 23(1), 105-108.

Moraes, P. H. G. et al. (2015). Molecular characterization of Babesia vogeli in dogs from Belém, northern Brazil. Genetics and Molecular Research, 14(4), 16364-71.

Nelson, R. W., \& Couto, C. G. (2015). Medicina Interna de Pequenos Animais. (5a ed.). Guanabara Koogan.

O’dwyer, L. H. \& Massard, C. L. (2002). Babesiose em pequenos animais domésticos e como zoonoses. In: ALMOSNY, N.R. Hemoparasitoses em pequenos animais domésticos e como zoonoses. LF Livros de Veterinária, p. 57-67.

Otranto, D. \& Dantas-Torres, F. (2010). Canine and feline vector-borne diseases in Italy: current situation and perspectives. Parasites \& Vectors, 3(2), 1-12.

Parola, P. et al. (2003). Detection of Ehrlichia spp., Anaplasma spp., Rickettsia spp., and other eubacteria in ticks from the Thai-Myanmar border and Vietnam. Journal of Clinical Microbioly. 41(4), 1600-8.

Santolin, I.D.A.C. (2014). Estudo de carrapatos associados com aves no entorno do tinguá, Nova Iguaçu, Rio de Janeiro, Brasil, detecção de Rickettsia spp., e o desenvolvimento de métodos moleculares para análise de interações carrapato-microrganismo. Tese de doutorado, Universidade Federal Rural do Rio de Janeiro.

Salgado, F. P. (2006). Identificação de hemoparasitos e carrapatos de cães procedentes do Centro de Controle de Zoonoses de Campo Grande, estado do Mato Grosso do Sul, Brasil. Dissertação. (Mestrado em Sanidade Animal) - Pós-graduação em Ciência Animal, Universidade Federal de Mato Grosso do Sul.

Sambrook, J. \& Russel, D. W. (2001). Molecular Cloning: A Laboratory Manual. (4a ed.). Cold Spring Harbor Laboratory Press.

Silva, A. B. et al. (2012) Detecção molecular de Babesia canis vogeli em cães e em Rhipicephalus sanguineus na mesorregião do oeste maranhense, nordeste brasileiro. Ciência Animal Brasileira. 13(3), 388-95.

Silva, J. M. A. S. et al. (2017) Ectoparasitas em Cães de Áreas Peri-rurais do Município de Rio Branco, Acre, Amazônia Ocidental. Enciclopédia Biosfera, Goiânia 14(26), 306-16.

Spolidorio, M. G. et al. (2013). Serosurvey for tick-borne diseases in dogs from the Eastern Amazon, Brazil. Revista Brasileira de Parasitologia Veterinária. 22(2), 214-9.

Tanikawa, A. et al. (2013). Ehrlichia canis in dogs in a semiarid region of Northeastern Brazil: Serology, molecular detection and associated factors. Research in veterinary Science, $94(3), 474-7$.

Vieira, F. T. (2017). Ocorrência de Ehrlichia spp., Anaplasma spp., Babesia spp., Hepatozoon spp. e Rickettsia spp. em cães domiciliados em seis municípios do estado do Espírito Santo, Brasil. 68 f. Tese (Doutorado em doenças infecciosas) - Universidade federal do Espírito Santo, Vitória. 